\title{
The relationship between dominance and spawning in Herotilapia multispinosa (Pisces: Cichlidae)
}

\author{
JANIS WILEY DRISCOLL and PHILIP R. WELANKO \\ University of Colorado, Denver, Colorado 80202
}

\begin{abstract}
The outcomes of fights between all possible pairs of same-sexed individuals were used to infer the within-sex dominance rank of six male and six female Herotilapia multispinosa. The resulting dominance hierarchies were compared with the order in which all 12 fish spawned when placed together in a large aquarium. Two replications of dominance rank assessment and spawning order were carried out. The spawning order of females was highly correlated with their dominance rank in both replications. Males spawned in a similar order in both replications but did not form a stable dominance hierarchy as inferred from the outcomes of fights. It is suggested that this finding may be due to the importance of site attachment in the agonistic behavior of male $H$. multispinosa.
\end{abstract}

Dominance has been defined as a relationship between individuals in which one has precedence over others in agonistic encounters and in access to resources. The definitions provided by a number of recent writers stress the importance of differential access to resources and its relation to reproductive success as the most basic aspect of dominance. For example, Wilson (1975) defines dominance as "the assertion of one member of a group over another in acquiring access to a piece of food, a mate, a place to display, a sleeping site or any other requisite that adds to the genetic fitness of the dominant individual." Similarly, Barlow and Ballin (1976) define dominance as "observable behavior that confers access to incentives," while Keenleyside (1979) defines dominance as "any behavior by which one animal gains priority over others in attaining a shared resource." If, as these writers suggest, the basis of dominance is differential access to resources, it should be possible to find high correlations among various measures of dominance. That is, the outcomes of agonistic interactions should correlate with the outcomes of competitive interactions, and the outcomes of different measures of competition should correlate with one another. Such correlations seem generally to hold for primates (e.g., Packer, 1979; Richards, 1974), although there are some complications (Rowell, 1974). For other species, the relationship between various measures of dominance is less consistent (Syme, 1974).

In fish, dominance has typically been inferred from agonistic encounters, and few studies have ex-

Address correspondence to Janis W. Driscoll, Division of Natural and Physical Sciences, University of Colorado at Denver, 1100 14th St., Denver, Colorado 80202. plored systematically the relationship between such encounters and resource acquisition or reproductive success. Ross and Reed (1978) reported a relationship between dominance and spawning success in male fallfish. High status was established through agonistic interactions previous to nest building and later was correlated with greater success in spawning. Weber and Weber (1975), in a study investigating the effects of female size, color, and dominance on mate selection in the convict cichlid (Cichlasoma nigrofasciatum), concluded that female dominance was a major factor in determining which of a group of four females paired with a single male. The purpose of the study reported here was to explore further the relationship between within-sex dominance, as inferred from agonistic interactions, and reproductive success, defined in terms of spawning order, for both male and female Herotilapia multispinosa.

\section{METHOD}

\section{Subjects}

Herotilapia multispinosa is a New World cichlid found on the Atlantic slope of Central America (Miller, 1966). The species shows behavior patterns typical of a biparental, hard-substrate spawner (Baerends \& Baerends-van Roon, 1950; Baylis, 1974; Brown \& Marshall, 1978; Smith-Grayton \& Keenleyside, 1978). The six male and six female fish used in this experiment were obtained locally. Prior to the experiment, they were housed with other fish in 170-liter aquariums. Water temperature was maintained at $21^{\circ}$ to $24^{\circ} \mathrm{C}$. A $12 / 12$ light-dark cycle with lights on from 0900 to 2100 was in effect throughout the experiment. Fish were fed daily on Tetramin flakes. Sex was determined by previous observation of spawning or by the shape of the female ovipositor, which is broad and blunt and can be differentiated from the male organ, which is slender and sharply pointed. Individuals were identified by a colored thread that was inserted through the base of the dorsal fin and tied in a loop large enough to permit fin erection. It was necessary to replace threads about every 2 weeks. 


\section{Procedure}

Within-sex dominance was assessed separately for male and female $H$, multispinosa by observing the outcomes of fights between all possible pairings of same-sexed individuals. Fights between pairs of individuals (dyads) were conducted in one of three identical 38-liter aquariums in which each dyad had been housed, separated by a plastic partition, for approximately $47 \mathrm{~h}$. Dyads were determined randomly with the restriction that no fish could have consecutive fights in the same aquarium. A fight began with the first interaction between the fish after the partition was removed and continued until the observer concluded that a clear dominance relationship had been established. This decision was based on the following three criteria. First, if a fish exhibited dark eye color while its opponent exhibited light eye color, it was considered the loser and its opponent was considered the winner. Second, if one fish chased the other, it was considered the winner and its opponent was considered the loser. Third, if a fish pushed its opponent more than it was pushed, it was considered the winner and its opponent was considered the loser. The behaviors providing the basis for these criteria have been shown to be important in this species by Driscoll and Welanko (1981). During the time that a tournament was being conducted with one sex, the members of the other sex were housed together in a 170-liter aquarium. At the conclusion of the three fights scheduled for a particular day, new dyads were selected, transferred to different aquariums, and again isolated until the next fight, which occurred about $47 \mathrm{~h}$ later.

Two complete round-robin tournaments in which each fish met each other fish of the same sex one time were conducted for males and for females. Dominance scores based on the number of fights won and lost by each fish in each tournament were used to rank the fish in hypothetical dominance hierarchies. This was done separately for male and female fish and for each round-robin tournament.

Following the completion of each dominance assessment phase (one round-robin tournament for each sex), all 12 fish were placed in a 265 -liter aquarium, measuring $120 \mathrm{~cm}$ long $\times 45 \mathrm{~cm}$ wide. This aquarium was provided with two flowerpot spawning sites, one at each end of the tank. As each pair of fish spawned, the members of that pair were removed with their eggs and flowerpot, and a new pot was placed in the vacated position. This procedure was continued until all six pairs had spawned. Assessment of spawning order followed each sequence of dominance assessment, providing two replications of spawning order.

Following the completion of the second assessment of spawning order, two additional round-robin tournaments were conducted with the six male fish. The procedures used for these tournaments were the same as those used earlier to assess dominance.

\section{RESULTS}

All of the fights in the two dominance assessment tournaments were resolved using the three criteria previously described. There were no instances in which a winner and a loser could not be specified, and there were no instances in which criteria disagreed as to the outcome. Chasing and fleeing behavior (Criterion 2) occurred infrequently, and this criterion was used in the resolution of only two fights involving females and one fight involving males. This result is consistent with the findings of Driscoll and Welanko (1981) that chasing and fleeing occur too infrequently in $H$. multispinosa to be useful in dominance assessment, at least in the setting used here. The length of fights was variable, with a mean length of $6.04 \mathrm{~min}$ and a standard deviation of $5.20 \mathrm{~min}$. A repeated-measures analysis of variance showed no significant differences in fight length for males and females or for the first and second assessments of dominance status.

Dominance scores based on fights won and lost by each fish in each tournament were used to rank the fish in hypothetical dominance hierarchies. Two ties, each involving two fish, occurred in the male hierarchy for the first tournament. These ties were resolved by using the outcome of the fight between the two tied fish in each case.

The similarity of the hierarchies produced in the two tournaments for males and females was evaluated using Spearman rank-order correlation coefficients (rho). One-tailed tests were used to evaluate the probabilities of these coefficients. The hierarchies for the two tournaments were similar for females (rho $=$ $.94, \mathrm{~N}=6, \mathrm{p}<.025$ ), but not for males ( $\mathrm{rho}=-.37$, $\mathrm{N}=6, \mathrm{p}>.05$ ).

Fish tended to spawn in the same order in both replications of spawning order. This was true for both males and females. For females, rho $=.89$, $\mathrm{N}=6, \mathrm{p}<.05$. For males, rho $=.83, \mathrm{~N}=6, \mathrm{p}<.05$. Four pairs of fish changed partners from the first spawning sequence to the second, while two pairs remained the same. Although two flowerpots were provided, there were no ties in spawning order. All 12 fish formed pairs and spawned in both replications.

Spearman rank-order correlation coefficients were used to evaluate the similarity between the dominance hierarchies inferred from fight outcomes and the order of spawning. In females, the dominance hierarchy was highly correlated with spawning order. For the first tournament and the first replication of spawning order, rho $=.89, \mathrm{~N}=6, \mathrm{p}<.025$. For the second tournament and second replication of spawning order, rho $=.94, N=6, p<.025$. The dominance hierarchies for males did not correlate significantly with the respective assessment of spawning order. For the first replication, rho $=.37$, and for the second replication, rho $=.43$.

Subsequent assessment of the male dominance order in two additional round-robin tournaments did not result in a stable dominance hierarchy. The dominance hierarchies inferred from the third and fourth tournaments did not correlate significantly with one another; nor did they correlate significantly with the dominance hierarchies inferred from Tournaments 1 and 2.

\section{DISCUSSION}

It is clear from the previous findings that a strong relationship exists between the within-sex dominance rank of female $\boldsymbol{H}$. multispinosa as inferred from the outcomes of fights and the order in which the females 
spawn. This could be produced in several ways. In this species, formation of pairs typically begins with the acquisition of a territory (here, a flowerpot) by a male. He then chooses or is chosen by a female, who joins him in territorial defense. It is possible that the relationship between female dominance and spawning order is produced because the territorial male chooses the dominant female. It is equally possible that the relationship is produced because the dominant female prevents other females from pairing with the territorial male. The latter suggestion has been made by Weber and Weber (1975) for Cichlasoma nigrofasciatum. It is also possible that some combination of these factors may be operating.

The lack of a relationship between spawning order and dominance rank in males is more puzzling. One possible explanation is that male $H$. multispinosa do not form stable dominance relationships. This seems unlikely because males acquire territory through fights with other males and typically are able to hold territory for long periods of time. It may be that, to form a dominance hierarchy, male $H$. multispinosa require a longer exposure to one another than do females. However, the third and fourth round-robin tournaments were no closer to producing a stable hierarchy than were Tournaments 1 and 2 , even though the same males had interacted throughout the entire sequence of experiments. It is possible that the males used in this experiment were too closely matched in their fighting ability to produce a stable dominance hierarchy. But, given that the males spawned in a similar order in the two replications of spawning order, a more reasonable explanation may be that the round-robin tournament procedure used here is an inadequate measure of dominance in male $\boldsymbol{H}$. multispinosa. The procedure used in dominance assessment (Driscoll \& Welanko, 1981) was specifically arranged to avoid site attachment and territoriality. It may be the case that site attachment is more important in the agonistic behavior of male $\boldsymbol{H}$. multispinosa than it is in that of females. In other words, males may not put their full efforts into defeating an opponent unless territory is involved. This would be consistent with a system in which the dominant male acquires and holds the most desirable territory. The dominant female may then be chosen by such a male or, more likely, may choose the male, the territory, or both by excluding subordinate females.

\section{REFERENCES}

Baerends, G. P., Baerends-van Roon, J. M. An introduction to the study of the ethology of cichlid fishes. Behaviour, 1950, 1, 1-242.

Barlow, G. W., \& Ballin, P. J. Predicting and assessing dominance from size and coloration on the polychromatic Midas cichlid. Animal Behaviour, 1976, 24, 793-813.

Baylis, J. R. The behavior and ecology of Herotilapia multispinosa (Teleostei, Cichlidae). Zeitschrift für Tierpsychologie, $1974,34,115-146$

Brown, D. H., \& Marshall, J. A. Reproductive behaviour of the rainbow cichlid, Herotilapia multispinosa (Pisces: Cichlidae). Behaviour, 1978, 67, 299-321.

Driscoll, J. W., \& WeLANKo, P. R. Dominance relationships in female Herotilapia multispinosa (Pisces: Cichlidae). Animal Learning \& Behavior, 1981, 9, 164-168.

KEENLEYside, M. H. A. Diversity and adaptation in fish behaviour. New York: Springer-Verlag, 1979.

Mille R, R. R. Geographical distribution of Central American freshwater fishes. In T. B. Thorson (Ed.), Investigations of the ichythyofauna of Nicaraguan lakes. Lincoln: School of Life Sciences, University of Nebraska, 1976. (Reprinted from Copeia, 1966, 4, 773-802.)

PaCken, C. Male dominance and reproductive activity in Papio anubis. Animal Behaviour, 1979, 27, 37-45.

RICHARDs, S. M. The concept of dominance and methods of assessment. Animal Behaviour, 1974, 22, 914-920.

Ross, M. R., \& REED, R. J. The reproductive behavior of the fallfish Semotilus corporalis. Copeia, 1978, 215-221.

ROWELL, T. E. The concept of social dominance. Behavioral Biology, 1974, 11, 131-154.

Smith-Grayton, P. K., \& Keenleyside, M. H. A. Male-female parental roles in Herotilapia multispinosa. Animal Behaviour, $1978,26,520-526$.

SYME, G. J. Competitive orders as measures of social dominance. Animal Behaviour, 1974, 22, 931-940.

Weber, P. G., \& Weber, S. P. The effect of female color, dominance and early experience upon mate selection in male convict cichlids [Cichlasoma nigrofasciatum Günther (Pisces: Cichlidae)]. Behaviour, 1975, 56, 116-135.

Wilson, E. O. Sociobiology. Cambridge, Mass: Belknap Press of Harvard University Press, 1975.

(Manuscript received March 3, 1981; revision accepted for publication June 23,1981 .) 